\title{
Radar GPR Application to Explore and Study Archaeological Sites: Case Study
}

\author{
Ahmed Faize $^{1}$, Gamil Alsharahi ${ }^{2}$, Mohammed Hamdaoui ${ }^{3}$ \\ Department of Physics \\ Polydisciplinary Faculty of Nador Mohammed First University, Morocco
}

\begin{abstract}
The issue of exploring and searching for archaeological sites is very important for a greater knowledge of the history of ancient nations and peoples. Recently, Ground Penetrating Radar GPR technology appeared to detect objects buried and study as depth as tens of meters. This work aims to apply this technique in studying and exploring some archaeological sites using the $500 \mathrm{MHz}$ antenna. This study has proven its effectiveness and success. Also, one of the important programs used in the processing of the obtained data is called Reflexw.
\end{abstract}

Keywords-Archaeological sites; exploring; ground penetrating radar; processing data

\section{INTRODUCTION}

Ground Penetrating Radar (GPR) is used to image the subsurface. It is a geophysical method based on the propagation, reflection and scattering of high frequency (from $10 \mathrm{MHZ}$ to $2.5 \mathrm{GHz}$ ) electromagnetic (EM) waves in the subsurface. The investigation depth depends on the EM wave attenuation, which grows as the conductivity of the subsoil materials increases, and on the frequencies used. Generally, the penetration depth is higher at lower frequency and varies from about $1 \mathrm{~m}$ to some tens of meters [1], [9].

We evaluate the applicability and the effectiveness of the GPR attribute analysis for archaeological purposes and we test the attribute analysis on GPR data obtained in the river harbor area of the Aquileia Archaeological Park, NE Italy, where the cultural heritage of the Roman imperial period is buried at different depths beneath a silty loam layer at an average depth not greater than 3-4 m [2]. During its development years, geophysical survey has served field archaeology by defining possible sites underground, before excavation or preservation. Now we can see the art taking off as a research method in its own right [3].

A ground-penetrating radar (GPR) survey, using mostly a $500 \mathrm{MHz}$ antenna, was carried out in an urban area (Lecce, Italy) to obtain a detailed characterization of the most superficial layers, where presumably archaeological structures are buried, and to quickly identify anomalous zones for excavation [4].

This technique has been successfully applied in GPR surveys along different archaeological sites such as: Roman buildings and other historical sites [5], [7]. They are commonly wide-open areas with large targets that often have a wellknown geometry. So usually these "Pseudo 3D" GPR surveys are based on the use of mid-low frequency antennas with a space between profiles of half a meter that involves a vast interpolation among data. Such methodology is generally considered sufficient to obtain images with enough resolution to show the profile of those archaeological targets [6], [8].

\section{Signal Processing}

The processing of the recorded results is done by a twostage signal processing process. First, a first processing is done on the radargrams, which allows the visualization of the underground data obtained directly by the GPR, thanks to the Reflexw software which uses standard filtering (Dewow, bandpass, gain improvement). Then, the data recovered after the passage of the Reflexw software, are processed by the GPR-Slice software, which is a software for processing images of slices in time [10]-[11]. Indeed, although the radargrams given by the Reflexw software, inform, in a satisfactory way, on the existence and the localization of the objects sought indepth, a meticulous and advanced 2D and 3D treatment proves to be extremely useful to access better results and interpretations.

\section{RESUlTS AND DISCUSSION}

In what follows, we describe the most notable results of the geophysical study conducted in:

\section{A. Zone 1}

The results of the B-Scans in Fig. 1(a) and (b) reveal the presence of strong horizontal secondary reflectors (red circles). We also note, in Fig. 1, an anomaly, green circle, characterized by the hyperbolic reflector with propagation speed equal to 0.1 $\mathrm{m} / \mathrm{ns}$ and vertex located at position $15.5 \mathrm{~m}$, from the origin of the radargram, and $0.6 \mathrm{~m}$ deep. Fig. 2(a) shows four time-slice representations (Time-Slice).

The area of the area is identified by $\mathrm{x}$ and $\mathrm{y}$, and the depth by time ranges from $0 \mathrm{~ns}$ to $20 \mathrm{~ns}$ ( $0 \mathrm{~m}$ to $1.8 \mathrm{~m}$ deep). The amplitudes, in absolute value, of the reflected signal, are represented by different colors, ranging from blue to orange. Gray is reserved for low amplitudes while yellow and orange are reserved for high amplitudes of signals returned by materials. The latter could be of natural or cultural origin.

At least four different rectangular structures seem to be present: the first is represented by a clear anomaly of $1 \mathrm{~m}$ in length and $1 \mathrm{~m}$ in width which is visible from $10 \mathrm{~ns}(0.5 \mathrm{~m}$ deep) up to $20 \mathrm{~ns}$ (1.8 $\mathrm{m}$ deep). The second structure is represented by an anomaly of $1 \mathrm{~m}$ in length and $1.4 \mathrm{~m}$ in width, visible from the same temporal depth as that indicated above. 
The third is a large anomaly $4 \mathrm{~m}$ long and $5 \mathrm{~m}$ wide. The last structure is $1 \mathrm{~m}$ long and $1.8 \mathrm{~m}$ wide.

Fig. 2(b) gives the general diagram of zone 1. This diagram represents the geometric structures suspected during the interpretation of the results given by the GPR. Analysis by 3D imagery (Fig. 3) confirms the presence of the anomalies observed in the radargrams and time slicer presentations.

\section{B. Zone 2}

The radargrams in Fig. 4 show a strong secondaryhorizontal reflector located at a depth of $0.9 \mathrm{~m}$ and located between $3.5 \mathrm{~m}$ and $8.2 \mathrm{~m}$, in the direction X. We also observe hyperbolas (speed of 0,06 at $0.1 \mathrm{~m} / \mathrm{ns}$ ), which may indicate other secondary reflectors.

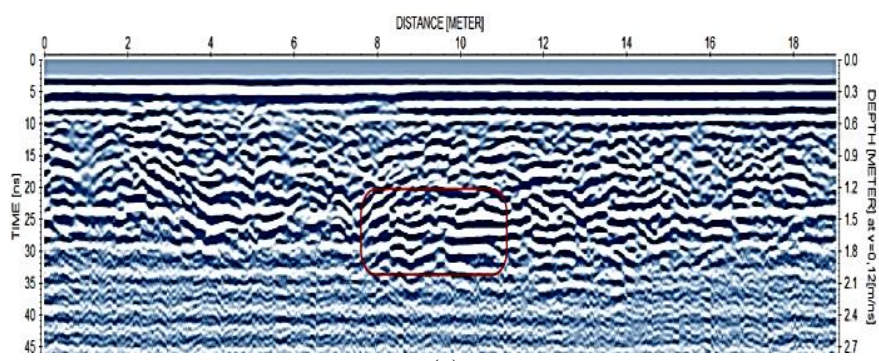

(a)

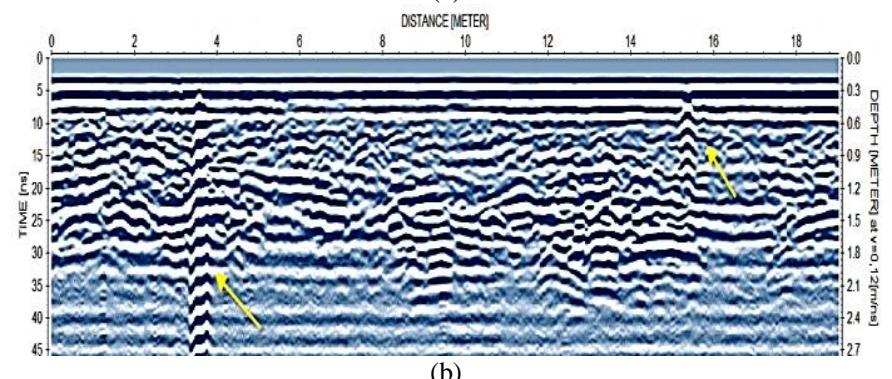

(b)

Fig. 1. Radargrams or B-Scans of Zone 1 Obtained using the $500 \mathrm{MHz}$ Antenna (a): The Red Square Encircles the Reflection on a Flat Surface, (b): The Yellow Arrows Indicate the Response of Shallow Metal Objects.

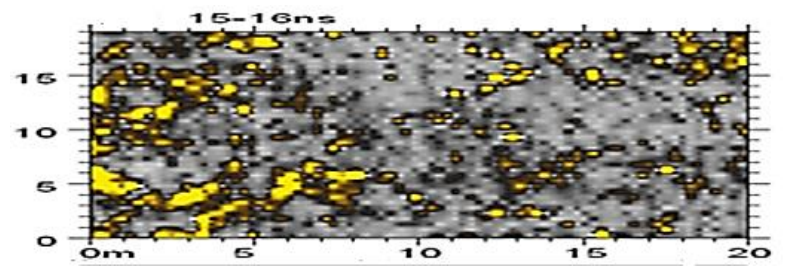

(a)

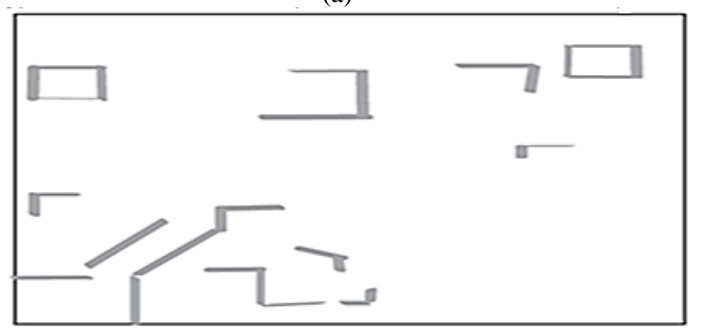

(b)

Fig. 2. (a) Time Slice or C-scan between 15 and 16 ns Obtained by the 500 $\mathrm{MHz}$ Antenna, (b) General Interpretation of Zone 1. We can Observe Rectangular Structures as well as Several Linear Anomalies.

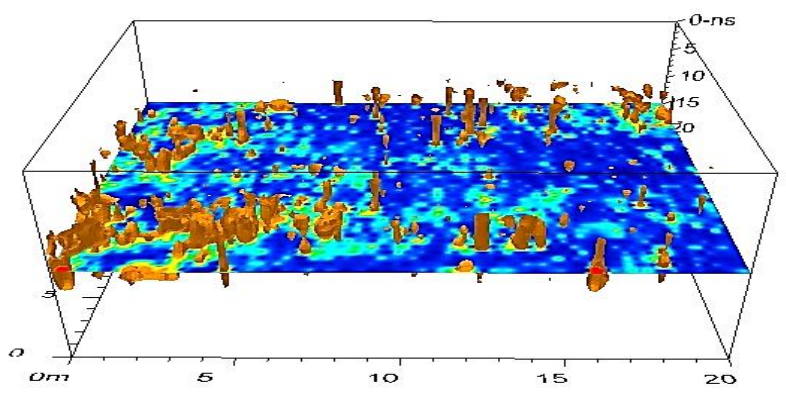

Fig. 3. GPR iso-Surface Slice Obtained using the $500 \mathrm{MHz}$ Antenna. We can Observe Four Small Rooms Around 15-17 ns.

The figure radargram (Fig. 4) shows a strong attenuation of the signal, between $15 \mathrm{~m}$ and $17 \mathrm{~m}$, which could be due to the presence of a mound at this level (red circle).

Fig. 5(a), in time slices, shows the presence of rectangular structures. The longer one, which can be associated with anomaly 1, becomes wider and deeper. This change in dimensions is probably due to a collapse somewhere in this structure. A wetter area (strongly attenuated signal) represented by a red circle in Fig. 4, corresponds to the mound already observed in the radargram given by the Reflexw software.

Fig. 5(b) gives the general diagram of zone 2. This diagram represents the geometric structures suspected during the interpretation of the results given by the GPR.

\section{Zone 3}

The radargrams obtained by the $500 \mathrm{MHz}$ antenna, illustrated in Fig. 6, reveal the presence of accentuated hyperbolas which indicate the presence of a long structure in the $\mathrm{X}$ direction (probably a wall).

On the radargram of Fig. 6, one can note, the presence of multiple reflections, which testify to the existence of several metallic fragments dispersed on the field of investigation, at a depth of $30 \mathrm{~cm}$. This complicates the task of exploring in this area. This "metallic" noise is observable in the 2D image.

Fig. 7 illustrates a slice in horizontal time going from 0 to $18 \mathrm{~ns}$. This time slot was constructed with the data collected by the $500 \mathrm{MHz}$ antenna. Strong radar reflection, coming from obstacles close to the surface $(0.4 \mathrm{~m})$, is observable on the 7 $18 \mathrm{~ns}$ bands. This signal would correspond to a modern utility gap hiding much of the potential characteristics.

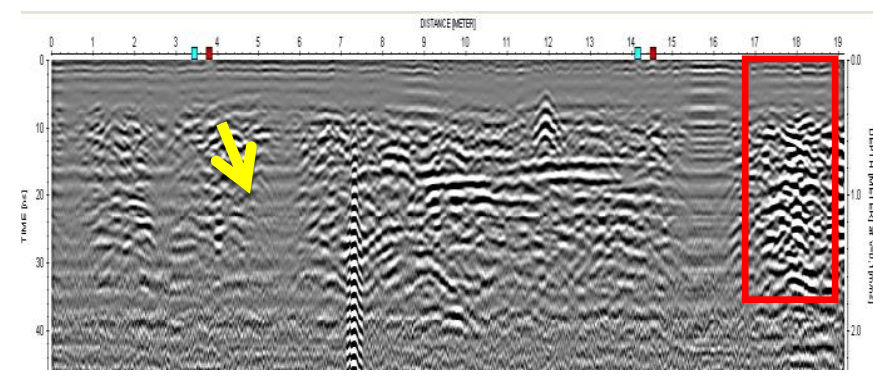

Fig. 4. Radargram or B-Scan of Zone 2 Processed by the $500 \mathrm{MHz}$ Antenna. between $\mathrm{X}=17 \mathrm{~m}$ and $\mathrm{X}=19$ we can Observe different Responses of the GPR Signal of a Structure (Probably a Wall). The Yellow Arrow Marks the Response of a Metallic Reflector and the Red Square Marks the Area where the Signal is Attenuated. 


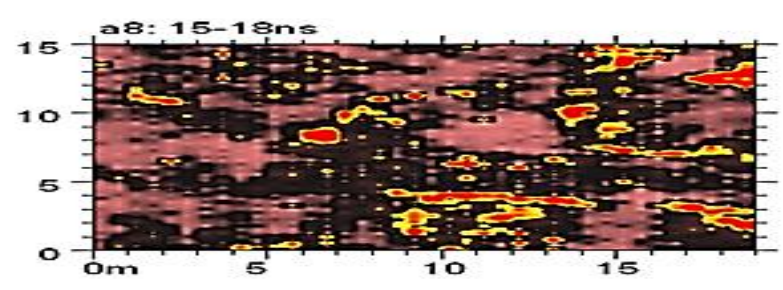

(a)

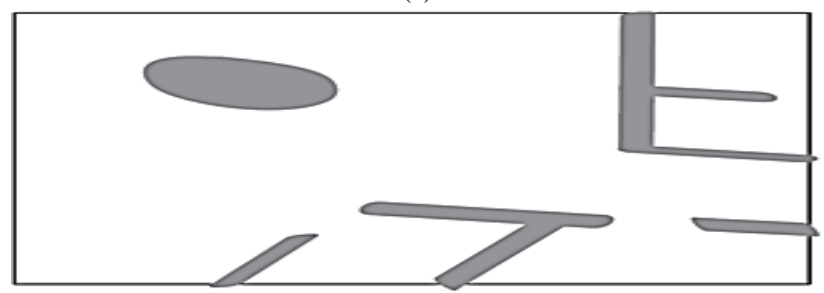

(b)

Fig. 5. (a) Time Section between 15 and $18 \mathrm{~ns}$ Obtained by the $500 \mathrm{MHz}$ Antenna in Zone 2, this Section Presents some Interesting Devices, such as a Long Linear Anomaly. In Addition, there is a Square Attached to this Linear Function which is Centered on $(\mathrm{X}=11 \mathrm{~m}, \mathrm{Y}=9 \mathrm{~m})$. (b) General Interpretation of Zone 2.

Analysis by 3D imagery (Fig. 8) confirms the presence of the anomalies observed in the radargrams and the time slice representations discussed above.

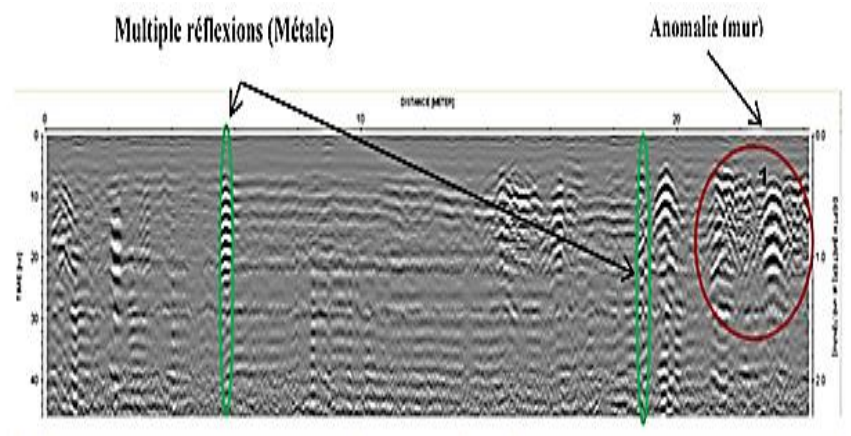

Fig. 6. Radargram in Zone 3 (a) of Line Number 13 Obtained with the 500 MHz Antenna. We can Observe a Linear Anomaly around 7 ns- 18 ns (Red Circle) and also Multiple Reflections (Green Circle).
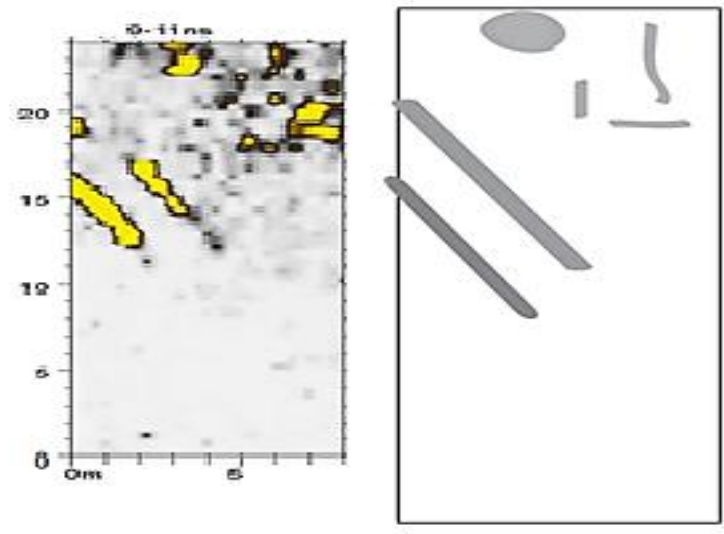

Fig. 7. Time Section of Area 16 at $7 \mathrm{~ns}-16 \mathrm{~ns}$ Obtained with the $500 \mathrm{MHz}$ Antenna in the Y Direction, (b) Illustration of the Time Section at 9-11ns and (c) General Interpretation of the Result in Zone 3. Two Parallel Anomalies Appeared at a Depth of $7 \mathrm{~ns}-16 \mathrm{~ns}$.

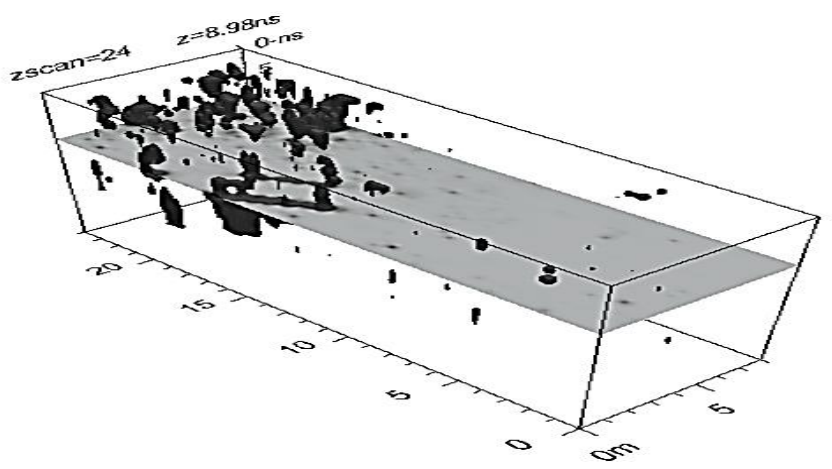

Fig. 8. GPR iso-Surface Slice Obtained in Time Windows 0-45ns with the $500 \mathrm{MHz}$ Antenna.

\section{CONCLUSION}

The sites studied are highly potential places from an archaeological point of view. They are indicated and recommended by specialists in the field of archeology. Analysis of the data collected by the GPR system, for the areas studied, reveals the presence of a significant amount of rectangular structures, long coasts, which can be interpreted, in this kind of sites, as archaeological remains, probably walls, chambers or remains of foundations.

However, it should be noted that certain areas of the sites studied were, in the past, places where modern activities were carried out, such as agriculture for example. The construction of greenhouses and warehouses has left scrap debris, which is buried at a shallow depth, which makes the interpretation of results (radargrams confused by parasitic signals caused by this debris extremely difficult.

\section{REFERENCES}

[1] BANNING, "Edward Bruce. Archaeological survey". Springer Science \& Business Media, 2002.

[2] W.Zhao, E.Forte, M.Pipan , G.Tian. "Ground penetrating radar (GPR) attribute analysis for archaeological prospection". Journal of Applied Geophysics, 2013, vol. 97, p. 107-117.

[3] CONYERS, Lawrence B. "Ground-penetrating radar for anthropological research". Antiquity, 2010, vol. 84, no 323, p. 175-184.

[4] V. Basile, M.T. Carrozzo, S. Negri, L. Nuzzo ), T. Quarta, A.V. Villani. "A ground-penetrating radar survey for archaeological investigations in an urban area (Lecce, Italy)". Journal of Applied Geophysics, 2000, vol. 44, no 1, p. 15-32.

[5] ALSHARAHI, Gamil, Ahmed Faize, Carmen Maftei, and Abdellah Driouach. "GPR Application for Risks Detection in Subsurface Engineering Construction Projects". Ovidius University Annals of Constanta-Series Civil Engineering 21, no. 1 (2019): 51-58.

[6] Nikos Papadopoulos, Apostolos Sarris, Myeong-Jong Yi1, Jung-Ho Kim. "Urban archaeological investigations using surface 3D ground penetrating radar and electrical resistivity tomography methods". Exploration Geophysics, 2009, vol. 40, no 1, p. 56-68.

[7] AlsharAhI, G., A. Faize, M. Louzazni, A. M. M. Mostapha, M. Bayjja, and A. Driouach. "Detection of cavities and fragile areas by numerical methods and GPR application". Journal of Applied Geophysics 164 (2019): 225-236.

[8] HOLCOMB, Derrold W. et SHINGIRAY, Irina Lita. "Imaging radar in archaeological investigations: An image processing perspective. In: Remote Sensing in Archaeology". Springer, New York, NY, 2006. p. 11-45.

[9] Alsharahi, Gamil, Ahmed Faize, Carmen Maftei, Mohamed Bayjja, Mohamed Louzazni, Abdellah Driouach, and Abdellatif Khamlichi. Analysis and "Modeling of GPR Signals to Detect Cavities: Case 
Studies in Morocco". Journal of Electromagnetic Engineering and Science 19, no. 3 (2019): 177-187.

[10] G. Alsharahi1, A. Mint Mohamed Mostapha, A. Faize, A. Driouach. "Modelling and simulation resolution of ground-penetrating radar antennas". Journal of electromagnetic engineering and science, 2016 vol. 16, no 3, p. 182-190.

[11] ALSHARAHI, Gamil, DRIOUACH, Abdellah, and FAIZE, Ahmed. "Performance of GPR influenced by electrical conductivity and dielectric constant”. Procedia technology, 2016, vol. 22, p. 570-575. 